\title{
STUDI TENTANG EFEK GREEN ADVERTISING PADA INTENSI MEMBELI DENGAN PERILAKU PEDULI LINGKUNGAN SEBAGAI MODERASI
}

\author{
Dwinita Laksmidewi \\ Fakultas Ekonomika dan Bisnis Universitas Katolik Indonesia Atma Jaya \\ Email:dwinita2010@yahoo.com
}

\begin{abstract}
This study aims to examine whether green advertising has positive effect on consumer behavior. The study uses an experimental method that consists of two studies. Study 1 results show that green advertising have positive effect on purchase intention, through the mediation of brand attitude and attitude toward advertising. Green behavior has a moderation role; green advertising has direct effect on purchase intention when consumers have a high green behavior. Study 2 shows that brand attitude will be higher when consumers have highenvironmental knowledge, and then should have a positive effect on purchase intention as the result.
\end{abstract}

Keywords: green advertising, green behavior, brand attitude

\begin{abstract}
Abstrak: Studi ini bertujuan meneliti apakah iklan bertema lingkungan (green advertising) memiliki efek yang positif terhadap perilaku konsumen. Penelitian menggunakan metode eksperimen yang terdiri dari 2 studi. Hasil studi 1 memperlihatkan bahwa green advertising berpengaruh positif terhadap intensi membeli, melalui mediasi brand attitude dan sikap terhadap iklan. Perilaku peduli lingkungan memiliki peran moderasi, green advertising dapat berpengaruh langsung terhadap intensi membeli pada konsumen yang memiliki perilaku peduli lingkungan yang sangat tinggi. Studi 2 menunjukkan bahwa apabila konsumen diberikan pengetahuan tentang isu lingkungan, maka green advertising akan berpengaruh positif terhadap brand attitude, yang kemudian berpengaruh terhadap intensi membeli.
\end{abstract}

Kata kunci: green advertising, perilaku peduli lingkungan, brand attitude

\section{PENDAHULUAN}

Tren pasar global saat ini makin mengarah pada produk ramah lingkungan. Masalah lingkungan, seperti degradasi sumber daya alam, menyusutnya cadangan hutan, hilangnya berbagai spesies biologi, dan ancaman serius pemanasan global menjadi perhatian banyak produsen saat ini. Hal ini mendorong mereka untuk menciptakan produk ramah lingkungan/ produk hijau.Saat ini konsumen dapat memilih berbagai produk yang lebih ramah lingkungan, seperti produk yang menggunakan unsur alam, tidak menggunakan bahan kimia yang berbahaya, berbasis kayu dan kertas yang bersertifikasi, atau produk daur ulang. Namun demikian, keberhasilan produk hijau dalam mengurangi masalah lingkungan tergantung pada sikap dan perilaku konsumen.

Upaya produsen produk hijau membujuk konsumen untuk menerapkan gaya hidup hijau dan membeli produknya, diwujudkan dengan promosi iklan yang bertema lingkungan (green advertising). Di Indonesia, salah satu produsen besar Unilever, melalui iklan merek Molto Ultra dengan moto "Sekali Bilas" mengingatkan pada konsumen yaitu 
PT Unilever Indonesia akan pentingnya menghemat air dalam kehidupan kita sehari-hari. Iklan Unilever yang disajikan oleh TV berdurasi 30 detik ini merupakan wujud kepedulian terhadap krisis air bersih di Indonesia, disamping untuk memasarkan produk Molto Ultra Sekali Bilas. Sebagai contoh lain, iklan top brand produk air mineral Aqua, mengajak konsumen untuk meremukkan botol kosong Aqua dan membuangnya pada tempatnya. Iklan ini ingin menunjukkan bahwa kemasan Aqua ramah lingkungan, disampin gjuga mengajak konsumen untuk menerapkan gaya hidup hijau dalam kehidupan sehari-hari.

Saat ini perhatian terhadap lingkungan tidak lagi hanya menjadi ideologi para aktivis lingkungan, namun telah menjadi bagian dalam kompetisi pasar, yang berpengaruh pada perilaku konsumen, termasuk konsumen Indonesia.Dengan semakin meningkatnya kesadaran konsumen Indonesia akan masalah lingkungan, maka pada penelitian mengenai efektifitas green advertising dalam kaitannya dengan perilaku hijau konsumen Indonesia perlu dilakukan. Studi ini bertujuan untuk menguji efektifitas green advertising dalam mempengaruhi perilaku konsumen. Sebagaimana penelitian terdahulu yang menunjukkan bahwa kepedulian terhadap lingkungan berpengaruh terhadap perilaku membeli produk hijau (Mostafa, 2007; Schuhwerk\&Lefkoff-Hagius, 1995; D'Souza \&Taghian, 2005), maka penelitian ini mempertimbangkan faktor perilaku peduli lingkungan, dan pengetahuan lingkungan.

\section{KAJIAN TEORI}

Green Advertising. Menurut Banerjee, at al (1995) mendefinisikan green advertising sebagai iklan yang memenuhi satu atau lebih kriteria: 1) secara eksplisit maupun implisit membahas hubungan antara produk / layanan dan lingkungan biofisik, 2) mempromosikan gaya hidup hijau dengan atau tanpa-menonjolkan produk / layanan, 3) menyajikan citra perusahaan akan tanggung jawab lingkungan. Beberapa hal yang penting dalam green advertising seperti: apa dimensi hijau dari produk jasa dalam iklan? Bagaimana pengiklan memposisikan produk pada dimensi hijau tersebut? Dan apa daya tarik yang digunakan untuk mempersuasi konsumen membeli produk berdasarkan dampaknya pada lingkungan? Dengan tujuan yang ingin disampaikan yaitu mempromosikan produk hijau, mempromosikan citra hijau perusahaan, dan mempengaruhi perilaku hijau konsumen seperti reduce, reuse, dan recycle (Banerjee et al., 1995).

Pesan green dalam green advertising diilustrasikan secara verbal dan visual sedemikian rupa yang bertujuan memberi persuasi pada konsumen agar berperilaku hijau atau membeli produk hijau. Kronrod, at al. (2012) mengamati adanya fenomena bahwa pesan lingkungan atau slogan pemasaran sosial kebanyakan disampaikan dengan kalimat asertif. Penelitian Konrod et al. (2012) ini menunjukkan bahwa apabila konsumen dapat menemukan adanya isu yang penting bagi mereka, maka pesan lingkungan tidak perlu disampaikan dengan kalimat asertif. Tetapi jika isu tidak dipandang penting, maka kalimat asertifakan lebih efektif.

Dalam menanggapi produk hijau, konsumen memiliki persepsi ambivalen terhadap produk hijau, antara lain mempersepsikan bahwa produk hijau lebih mahal, berkualitas rendah, dan merasa sangsi akan keampuhan produk mengatasi masalah lingkungan (Chang, 2011). Persepsi ambivalensi ini berpengaruh pada respon konsumen terhadap green advertising. Sehingga pada konsumen dengan persepsi ambivalen yang rendah, efek green advertising menjadi lebih negatif (Chang, 2011). 
Beberapa penelitian bertema lingkungan belakangan ini membuat keterkaitan antara konsumen dengan alam secara antropomorfik, terbukti efektif memberikan persuasi pada konsumen. Tam, et al. (2013) menunjukkan bahwa masalah lingkungan alam yang disampaikan dengan memuat tulisan yang mendeskripsikan alam sebagai manusia, atau gambar alam yang diilustrasikan memiliki ciri fisik manusia, dapat meningkatkan perasaan terhubung dengan alam, yang kemudian berpengaruh terhadap perilaku peduli terhadap lingkungan. Dalam studi Tam et al. (2013), berita yang menuliskan alam sebagai Mr. dan menyebut alam sebagai "dia" menimbulkan perasaan terhubung dengan alam, dan kemudian mempunyai pengaruh yang signifikan terhadap perilaku peduli lingkungan. Poster mengenai konservasi energi yang dibuat menampilkan gambar bolam lampu dengan ciri wajah manusia, membuat intensi berperilaku lebih positif (Ahn, at al. 2013). Tam et al. (2013) dan Ahn et al. (2013) berupaya membuat masalah sosial seperti konservasi energi direspon positif oleh konsumen, dengan menggunakan pendekatan antropomorfisme, suatu kecenderungan konsumen menilai obyek yang bukan manusia memiliki karakteristik dan emosi manusia. Menampilkan gambar tempat sampah sedang menangis atau pohon menyerupai manusia, dapat menimbulkan responprososial yang positif bahkan membuat konsumen bersedia memberikan donasi (Ahn et al., 2013).

Perilaku Peduli Lingkungan. Studi Schuhwerk dan Lefkoff-Hagius (1995) menunjukkan bahwa efek iklan green dengan non-green berbeda pada konsumen menurut keterlibatan mereka dengan lingkungan.Bagi konsumen yang memiliki keterlibatan tinggi dengan lingkungan efek iklan green/non green tidak berbeda signifikan pada sikap terhadap iklan dan juga intensi membeli. Sebaliknya pada konsumen dengan keterlibatan rendah iklan green lebih persuasif bagi mereka, dibandingkan iklan non green. Di Indonesia, penelitian tentang apakah perilaku atau keterlibatan konsumen dengan lingkungan turut berperan di dalam efek green advertising, belum dilakukan.

Perilaku peduli lingkungan mencakup tidak hanya green consumption, melainkan juga mencakup perilaku kebiasaan sehari-hari (Gilg et al., 2005). Termasuk dalam green consumption seperti membeli produk organik, menghindari produk yang mengandung aerosol, membeli produk kertas yang dapat didaur ulang, juga hal lain yang terkait dengan membeli green product. Perilaku peduli lingkungan dalam penelitian ini mencakup juga menghemat energi, penanganan limbah, dan konservasi air, yang diistilahkan sebagai sustainable lifestyles oleh Gilg et al. (2005). Membeli green product dilakukan secara sadar oleh konsumen, sedangkan mematikan lampu atau AC merupakan aktivitas kebiasaan yang unconscious, dan terkait dengan nilai altruistik konsumen (Gilg et al., 2005). Peneliti sebelumnya menggunakan istilah green lifestyle, yang pengertiannya mencakup penilaian tentang dampak lingkungan dari produk atau jasa, dan perubahan perilaku dalam membeli, mengkonsumsi, dan membuang produk (Banerjee et al., 1995).

Berbeda dengan Schuhwerk dan Lefkoff-Hagius (1995), pada penelitian D'Souza dan Taghian (2005) konsumen dengan keterlibatan lingkungan yang rendah lebih mengabaikan green advertising. Sebaliknya konsumen dengan keterlibatan lingkungan yang tinggi menilai bahwa green ad lebih menyenangkan, bagus, informatif, meyakinkan, dan dapat dipercaya, namun menurut kelompok konsumen ini, green ad tidak meyakinkan, dan tidak berpengaruh pada citra perusahaan.

Penelitian terdahulu mengenai green marketing, sebagian terfokus pada meneliti karakteristik konsumen.Tingkat pendidikan, usia, gender, dan kemampuan ekonomi konsumen menunjukkan perilaku kepedulian lingkungan yang berbeda. Konsumen dengan pendidikan yang tinggi, berusia dewasa, perempuan, dan berpendapatan tinggi lebih peduli 
terhadap permasalahan lingkungan (Gilg et al., 2005). Namun, nilai green yang dipahami dan dianut oleh konsumen tidak selalu berkorelasi positif dengan perilakunya (Young, et al, 2010).Konsumen yang peduli dengan isu lingkungan, hanya sebagian kecil yang mewujudkannya dalam bentuk perilaku membeli produk hijau (Young et al., 2010). Ini membuat produk hijau hanya mendapatkan pangsa pasar yang kecil. Penelitian kualitatif dengan depth interviews yang dilakukan Young et al. (2010) di UK menunjukkan bahwa menjadi "green" membutuhkan proses, gaya hidup yang sibuk membuat green effort konsumen menjadi rendah. Sehingga menurut mereka diperlukan usaha pemasar seperti pemberian insentif, memasang label green seperti label tingkat energi, agar dapat menarik konsentrasi konsumen dan mendorong perilaku green .

Pengetahuan ekologi, orientasi lingkungan alam, dan kepedulian terhadap lingkungan pada penelitian Mostafa (2007) berpengaruh signifikan terhadap sikap berperilaku membeli produk hijau. Kemudian sikap tersebut mempengaruhi perilaku membeli dengan intensi membeli produk hijau sebagai mediasi. Namun pada penelitian Mustofa (2007) pada konsumen Egypt ini, hubungan antara intensi membeli produk hijau dan perilaku aktual lemah, walaupun konsumen menyatakan bahwa mereka mempunyai kepedulian terhadap lingkungan dan ingin berkontribusi terhadap proteksi lingkungan tetapi tidak diwujudkan dengan perilaku membeli.

Pada segmen konsumen tertentu, kepedulian terhadap lingkungan diwujudkan dengan perilaku yang istimewa. Dalam Laroche, Bergeron dan Barbaro-Forleo (2001), konsumen bahkan bersedia membayar lebih mahal untuk produk ramah lingkungan. Faktor-faktor konsumen yang mempengaruhi kesediaan konsumen membayar lebih mahal untuk produk ramah lingkungan meliputi faktor demografis, pengetahuan, nilai, sikap, dan perilaku. Segmen konsumen ini adalah perempuan, menikah, memiliki anak minimal satu, dan mereka menolak membeli produk dari perusahaan yang menyebabkan polusi (Laroche et al., 2001). Di Indonesia, melalui kegiatan corporate social responsibility (CSR), berbagai upaya dilakukan perusahaan untuk meningkatkan kepedulian konsumen terhadap lingkungan. Namun masih diperlukan penelitian yang lebih luas dan mendalam mengenai bagaimana tingkat green konsumen Indonesia, bagaimana profil mereka, serta bagaimana respon konsumen terhadap berbagai stimulusgreen yang diupayakan baik oleh pemerintah maupun perusahaan swasta.

Pengiklan dapat menonjolkan manfaat lingkungan dari produk dalam iklan, agar menciptakan citra tanggungjawab lingkungan perusahaan yang positif (Banerjee et al., 1995).Walaupun demikian, tanggungjawab sosial perusahaan dalam beberapa kondisi justru dapat menurunkan intensi membeli produk (Sen \& Bhattacharya, 2001). Persepsi konsumen akan kecocokan nilai diri dan perusahaan menjadi mediasi pengaruh usaha tanggungjawab sosial perusahaan terhadap intensi membeli (Sen \& Bhattacharya, 2001). Jika antara nilai diri dan perusahaan dianggap inkongruen maka justru akan menurunkan intensi membeli. Maka dapat diartikan bahwa kesesuaian antara brand dan nilai diri konsumen (Aaker, 1997; Fournier, 1998) berperan dalam efek green ad terhadap perilaku konsumen. Oleh karena itu penelitian ini mempertimbangkan variabel brand attitude sebagai mediasi.

Pengaruh Iklan Pada Sikap Terhadap Iklan, Brand Attitude dan Intensi Membeli. Efektivitas sebuah iklan dapat diukur dari bagaimana pengaruhnya pada sikap konsumen terhadap merek (Lutz, MacKenzie, \& Belch, 1983).Ketika menerima eksposur sebuah iklan, konsumen akan membangun sikap terhadap iklan, kemudian sikap konsumen 
terhadap iklan tersebut mempengaruhi sikapnya terhadap merek $\left(\mathrm{A}_{\mathrm{B}}\right)$, dan intensi membeli. Model Lutz et al. (1983) didasarkan pada teori perubahan sikap Petty et al. (1983), dimana terdapat dua rute dasar untuk perubahan sikap konsumen yaitu rute sentral dan periferal. Rute sentral merupakan hasil dari keaktifan berpikir konsumen tentang konten pesan iklan, sedangkan rute periferal merubah sikap melalui aspek tambahan seperti kredibilitas, dan kemenarikan iklan. Sikap konsumen terhadap merek dipengaruhi oleh sikapnya terhadap iklan melalui proses periferal, dan dipengaruhi oleh persepsi konsumen terhadap merek melalui proses sentral.Konsumen yang memiliki motivasi dan kemampuan yang tinggi ketika mendapat eksposur iklan akan terpengaruh kepercayaannya terhadap merek, yang kemudian mempengaruhi intensi membeli. Sebaliknya jika motivasi dan kemampuan rendah, iklan lebih mempengaruhi sikapnya terhadap iklan, yang kemudian mempengaruhi sikap terhadap merek dan intensi membelinya (Lutz et al., 1983).

Hipotesis 1: Pengaruh green advertising terhadap intensi membeli dimediasi oleh sikap terhadap iklan $\left(\mathrm{A}_{\mathrm{ad}}\right)\left(\mathrm{H}_{1 \mathrm{a}}\right)$, dan brand attitude $\left(\mathrm{H}_{1 \mathrm{~b}}\right)$.

Konsumen merespongreen advertising secara berbeda-beda.Iklan green dengan nongreen berbeda efek pada konsumen menurut keterlibatan mereka dengan lingkungan (Schuhwerk\&Lefkoff-Hagius, 1995; Mostafa, 2007; D'Souza \&Taghian, (2005) dan menurut persepsi ambivalensi terhadap green product(Chang, 2011).

Hipotesis 2: Pengaruh green advertising terhadap intensi membeli dimoderasi oleh perilaku peduli lingkungan

Pengetahuan lingkungan meliputi apa yang diketahui konsumen mengenai lingkungan, aspek-aspek, dampak, dan tanggung jawab kolektif yang diperlukan untuk pembangunan berkelanjutan (Mostafa, 2007).Pada penelitian mengenai green marketing, pengetahuan konsumen tentang lingkungan berpengaruh pada sikap perilaku membeli produk hijau.Pemasar dapat menambahkan pengetahuan lingkungan konsumen dengan memutar video klip tentang lingkungan dan memiliki efek positif pada respon konsumen (Konrod et al., 2011).

Hipotesis 3: Pada konsumen dengan pengetahuan lingkungan yang lebih tinggi, green advertising membentuk brand attitude dan intensi membeli lebih positif dibandingkan pada konsumen dengan pengetahuan lingkungan yang rendah.

Studi 1. Studi 1 bertujuan untuk menguji apakah green advertisingberpengaruh terhadap intensi membeli, dengan melalui mediasi sikap terhadap iklan, dan brand attitude (H1).Disamping itu studi 1 bertujuan untuk menguji apakah pengaruh green advertising terhadap intensi membeli dimoderasi oleh perilaku peduli lingkungan $(\mathrm{H} 2)$.

\section{METODE}

Desain Penelitian dan Partisipan. Penelitian dilakukan dengan metode eksperimen, dengan dua kondisi eksperimen (advertising: green versus non-green) between participants. Variabel yang diukur adalah sikap terhadap iklan, brand attitude, intensi membeli, dan perilaku peduli lingkungan.Partisipan penelitian ini adalah 100 mahasiswa (46 laki-laki dan 54 perempuan) Fakultas Ekonomika dan Bisnis Unika Atma Jaya Jakarta, berusia 17 - 21 tahun, yang ditempatkan secara random pada satu dari dua kelompok kondisi. 
Stimulus. Untuk penelitian ini dibuat dua iklan cetak produk air mineral dalam kemasan botol. Sebelumnya penulis melakukan pilot studi untuk menentukan produk yang sering dibeli sendiri oleh partisipan, dengan frekuensi tertinggi produk air mineral. Menggunakan tema green dari iklan produk air mineral yang telah ada. Pada studi ini digunakan merek produk riil dengan tujuan agar dapat membedakan efek iklan bertema green dan nongreen. Untuk tujuan serupa penulis memilih satu merek yang bukan top brand pada industri air minum dalam kemasan. Merek tersebut dicantumkan dalam iklan stimulus, namun dalam tulisan ini penulis menggunakan inisial merek "A". Stimulus untuk kondisi green adalah iklan cetak yang pada bagian tengah tulisannya bertuliskan "Remukkan. Rasakan serunya meremukkan botol ini. Botol yang diremukkan memakai lebih sedikit ruang". Sedangkan stimulus kondisi non-green dibuat iklan cetak yang pada bagian tengahnya bertuliskan "Rasakan Serunya minum A". Pada iklan green diawali dengan tulisan "Seperti Apa Bentuk Kepedulianmu Terhadap Lingkungan?", sedangkan pada iklan non-green diawali dengan tulisan "Seperti Apa Bentuk Kepedulianmu Terhadap Kesehatan?". Kedua iklanstimulus diakhiri dengan tulisan yang sama, yaitu "Langkah Kecil Memberikan Perubahan". Iklan untuk kedua stimulus dibuat hitam putih, agar selera warna tidak berpengaruh, bergambar sebuah botol produk air mineral pada sisi kiri, dan tulisan di sisi kanan, menggunakan merek yang sama, pada kertas berukuran 8.27'x 11.69".

Prosedur dan Alat Ukur. Partisipan datang secara berkelompok terdiri dari 5-8 orang per kelompok. Partisipan menempati meja yang telah diberi stimulus dan 1 set formulir salah satu kondisi eksperimen, dengan penempatan kondisi acak. Eksperimenter membuka penelitian, dan menyampaikan bahwa penelitian ini bertujuan untuk mengevaluasi sebuah iklan. Setelah mengisi informed consent, partisipan diminta mengisi pertanyaan mengenai perilaku peduli lingkungan. Pertanyaan ini diberikan di awal agar mencerminkan kondisi awal partisipan, dan tidak terpengaruh oleh stimulus. Selanjutnya partisipan diminta mengamati stimulus selama beberapa saat, dimana sebelumnya partisipan diberitahu bahwa setelah melihat stimulus, mereka akan diminta menuliskan apa yang mereka lihat di iklan. Tahap selanjutnya adalah mengisi formulir pertanyaan utama mengenai sikap terhadap iklan, brand attitude, intensi membeli, diakhiri dengan mengisi manipulation check dan data demografis.

Intensimembeli diadaptasi dari skala intensimembeli Fishbein dan Ajzen (1975), terdiri dari 2 item pertanyaan, salah satunya yaitu saya akan membeli A. Sikap terhadap iklan $\left(\mathrm{A}_{\mathrm{ad}}\right)$ menggunakan skala sikap terhadap iklan Homer (1995) terdiri dari 4 item $(\alpha=0.839)$ : iklan " $\mathrm{A}$ " ini menarik, informatif, mudah dipahami, bagus.Brand attitude diadaptasi dari Miniard et al. (1991) dengan 3 item $(\alpha=0.830)$ antara lain: saya suka A, A baik. Sedangkan skala perilaku peduli lingkungan diadaptasi dari Gilg, Barr, dan Ford (2005); Schuwerk dan Lekoff-Hagius (1995), terdiri dari 16 item $(\alpha=0,764)$, antara lain: saya mematikan keran air ketika sedang memakai sabun cuci tangan, saya mematikan lampu ketika ruang sedang tidak digunakan, saya menggunakan kembali kertas yang masih kosong, saya menggunakan kembali tas plastik bekas. Semua item menggunakan skala Likert 6 poin: sangat tidak setuju/sangat setuju. 


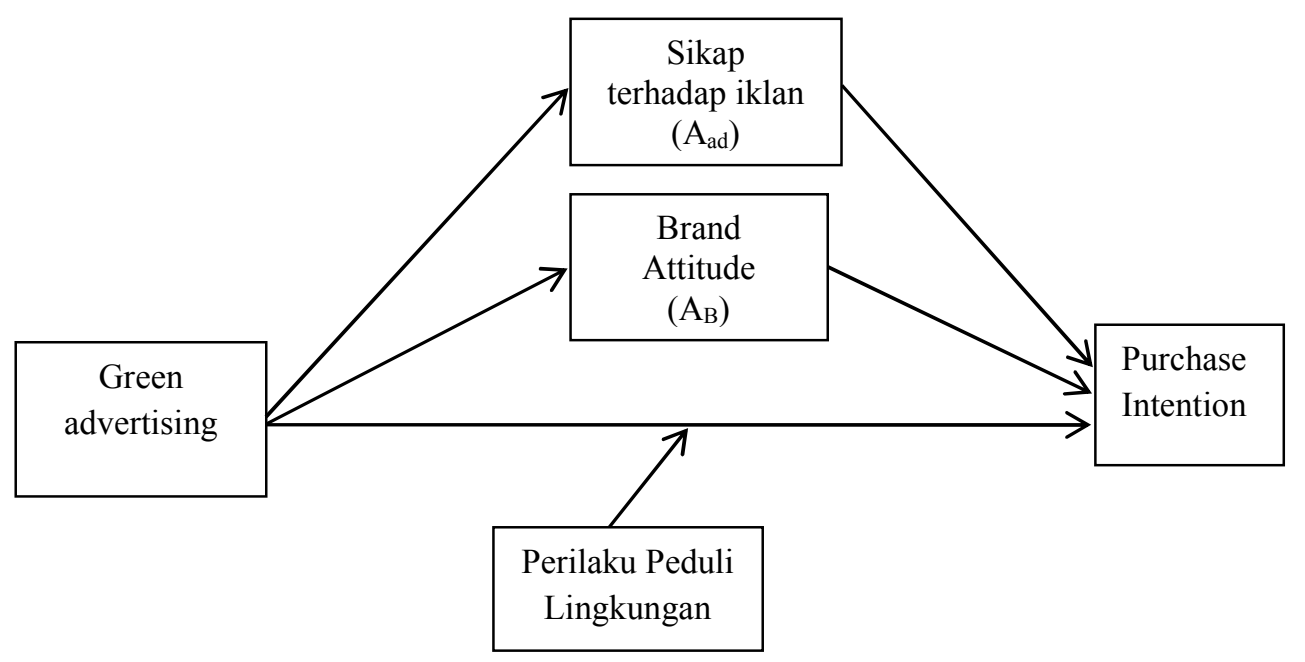

Gambar 1. Model Konseptual Studi 1

\section{HASIL DAN PEMBAHASAN}

Manipulation Check. Sebagai manipulation check dilakukan pengukuran tingkat green dari iklan stimulus dengan empat item $(\alpha=0.942)$ : dalam iklan "A"ramah lingkungan, menganjurkan gaya hidup peduli lingkungan, memperlihatkan tanggung jawab lingkungan, dan menganjurkan tindakan peduli lingkungan. Hasil perhitungan ANOVA menunjukkan bahwa terdapat perbedaan mean pada dua kelompok kondisi $(F(1,98)=$ 226.921; $p=0.000)$. Tingkat green pada kondisi green signifikan lebih tinggi dibandingkan kondisi non-green $\left(M_{\text {green }}=5.1650 ; M_{\text {non-green }}=3.2550\right)$. Hasil ini menunjukkan bahwa manipulasi bekerja dengan baik pada eksperimen yang dilakukan.

Sikap Terhadap Iklan, Brand Attitude, Dan Intensi Membeli. Sikap terhadap iklan green signifikan lebih tinggi dibanding iklan non-green $(F(1,98)=26.727, p=0.000$, $\left.M_{\text {green }}=4.7200 ; M_{\text {non-green }}=3.9300\right)$. Iklan green dinilai lebih menarik, informatif, mudah dipahami, dan bagus.Sikap partisipan terhadap merek "A" juga signifikan lebih tinggi pada kondisi green, dibandingkan pada kondisi non-green $(F(1,98)=10.833, p=0.001$, $\left.M_{\text {green }}=4.6600 ; M_{\text {non-green }}=4.2400\right)$. Demikian pula intensi membeli produk pada kondisi iklan green lebih tinggi signifikan dibandingkan pada kondisi non-green $(F(1,98)=4.004$, $\left.p=0.048, M_{\text {green }}=3.5900 ; M_{\text {non-green }}=3.2400\right)$. Ini berarti tema kepedulian terhadap lingkungan pada iklan dapat membuat evaluasi konsumen terhadap iklan dan produk menjadi lebih baik, jika dibandingkan tema manfaat produk pada iklan.

Uji Hipotesis. Pengujian hipotesis mediasi dan moderasi pada studi ini menggunakan regresi OLS dengan SPSS macro PROCESS model 5 (Hayes, 2013; Hayes \& Preacher, 2013), dengan gambar model konseptual seperti pada Gambar 1. Langkah pengujian mediasi dan moderasi mengikuti Zhao et al. (2010), uji signifikansi menggunakanpendekatan bootstrapdengan $n=1000$ (Hayes \& Preacher, 2013).Sebagai variabel independen adalah green advertising, dengan dua kategori. Intensi membeli sebagai variabel dependen.Variabel mediasi adalah sikap terhadap iklan $\left(\mathrm{A}_{\mathrm{ad}}\right)$, dan brand Attitude $\left(\mathrm{A}_{\mathrm{B}}\right)$. Sedangkan perilaku peduli lingkungan sebagai variabel moderator. 
Hasil menunjukkan kondisi green (relatif terhadap non-green) pada iklan atau green advertisingberpengaruh signifikan pada sikap terhadap iklan $\left(\mathrm{A}_{\mathrm{ad}}\right)(b=0.7900, S E=0.1528$, $t=5.1698, p=0.000)$, dan berpengaruh signifikan pada brand attitude $\left(\mathrm{A}_{\mathrm{B}}\right)(b=0.4200$, $S E=0.1276, t=3.2913, p=0.0014)$. Sikap terhadap iklan $\left(\mathrm{A}_{\mathrm{ad}}\right)(b=0.2289, S E=0.0983, t=$ $2.3274, p=0.0221)$, dan brand attitude $\left(\mathrm{A}_{\mathrm{B}}\right)(b=0.5692, S E=0.1239, t=4.5930, p=0.000)$, berpengaruh signifikan terhadap intensi membeli (Tabel 1). Direct effect kondisi green (relatif terhadap non-green) pada iklan terhadap intensi membeli signifikan $(b=3.1050$, $S E=1.4182, t=2.1893, p=0.0311$ ). Indirect effect kondisi green (relatif terhadap nongreen) pada iklan pada intensi membeli, melalui $\mathrm{A}_{\mathrm{ad}}$ signifikanyang ditunjukkan dengan excluded zero confidence interval ( $a b=0.1808, \mathrm{SE}=0.0858,95 \% \quad C I[0.0349 ; 0.3605]$ ). Begitu pula indirect effect green advertising padaintensi membeli, melalui $\mathrm{A}_{\mathrm{B}}$ signifikan $(a b=0.2391, \mathrm{SE}=0.0813,95 \% C I[0.1088 ; 0.4495])$. Hasil ini menunjukkan bahwa $\mathrm{H} 1_{\mathrm{a}}$ dan $\mathrm{H} 1_{\mathrm{b}}$ didukung data.

Interaksi green advertising dengan perilaku peduli lingkungan signifikan $(b=-$ 0.6893, $S E=0.3077, t=-2.2401, p=0.0274$ ). Hal ini menunjukkan bahwa perilaku peduli lingkungan memoderasi pengaruh green ad terhadap intensi membeli, $\mathrm{H} 2$ didukung data.

Tabel 1. Studi 1- Sikap Terhadap Iklan $\left(A_{a d}\right)$ Dan Brand Attitude $\left(A_{B}\right)$ Sebagai Mediator

\begin{tabular}{|c|c|c|c|c|c|c|}
\hline & & \multirow{2}{*}{$\begin{array}{l}A_{a d} \\
\text { Koefisien } \\
\quad(S E)\end{array}$} & & \multirow{2}{*}{$\begin{array}{l}A_{B} \\
\text { Koefisien } \\
\quad(S E)\end{array}$} & \multicolumn{2}{|c|}{ Intensi Membeli } \\
\hline & & & & & & $\begin{array}{c}\text { Koefisien } \\
(S E)\end{array}$ \\
\hline Konstanta & $i_{1}$ & $\begin{array}{c}3.9300^{*} \\
0.1081\end{array}$ & $i_{2}$ & $\begin{array}{c}4.2400^{*} \\
0.0902\end{array}$ & $i_{3}$ & $\begin{array}{c}-3.4121^{* *} \\
1.0968\end{array}$ \\
\hline Dummy & $a_{l}$ & $\begin{array}{c}0.7900^{*} \\
0.1528\end{array}$ & $a_{2}$ & $\begin{array}{c}0.4200 * * \\
0.1276\end{array}$ & $c_{1}$ & $\begin{array}{c}3.1050^{* *} \\
1.4182\end{array}$ \\
\hline$A_{a d}$ & & & & & $b_{1}$ & $\begin{array}{c}0.2289 * * \\
0.0983\end{array}$ \\
\hline$A_{B}$ & & & & & $b_{2}$ & $\begin{array}{c}0.5692 * \\
0.1239\end{array}$ \\
\hline
\end{tabular}

Lebih lanjut, dilakukan probing terhadap interaksi ini untuk mengetahui range tingkatan perilaku peduli lingkungan dimana green ad memiliki efek signifikan terhadap intensi membeli (Tabel 2). Melakukan spotlight analysis pada perilaku peduli lingkungan persentil ke 10, 25, 50, 75, dan ke 90 (Spiller \& Lynch, 2013; Hayes, 2013), yaitu pada perilaku peduli lingkungan 4.0000 (sangat rendah), 4.2500 (rendah), 4.6250 (sedang), 5.0000 (tinggi), dan 5.3125 (sangat tinggi). Hasil spotlight analysis menunjukkan bahwa green ad memiliki efek signifikan terhadap intensi membeli hanya pada tingkat perilaku peduli lingkungan yang sangat tinggi ( $\mathrm{t}=-1.9983, \mathrm{p}=.0486,95 \% \mathrm{CI}[-1.1106 ;-.0035])$, sedangkan pada tingkat perilaku peduli lingkungan (green behavior) yang sangat rendah, rendah, sedang, dan tinggi, tidak signifikan.

Diskusi. Hasil studi 1 menunjukkan bahwa green advertising berpengaruh signifikan terhadap intensi membeli pada konsumen yang memiliki perilaku kepedulian lingkungan yang sangat tinggi. Seperti dikatakan oleh Young et al. (2010) bahwa perilaku green membutuhkan waktu dan proses, sehingga pemasar tentunya tidak dapat berharap bahwa pasar sasarannya memiliki perilaku peduli lingkungan yang semua tinggi. 
Tabel 2. Conditional direct effect green advertising terhadap intensi membeli padaperilaku peduli lingkungan persentil

ke $10,25,50,75$, dan ke 90

\begin{tabular}{ccccccc}
\hline $\begin{array}{c}\text { Green } \\
\text { Behavior }\end{array}$ & Efek & $S E$ & $t$ & $p$ & LLCI & ULCI \\
\hline 4.0000 & 0.3477 & 0.2415 & 1.4397 & 0.1533 & -0.1318 & 0.8271 \\
4.2500 & 0.1753 & 0.1920 & 0.9133 & 0.3634 & -0.2058 & 0.5565 \\
4.6250 & -0.0832 & 0.1639 & -0.5074 & 0.6131 & -0.4086 & 0.2423 \\
5.0000 & -0.3417 & 0.2086 & -1.6380 & 0.1048 & -0.7558 & 0.0725 \\
5.3125 & -0.5571 & 0.2788 & -1.9983 & 0.0486 & -1.1106 & -0.0035 \\
\hline
\end{tabular}

*significant $95 \%$ confidence limit excluded 0

Penelitian terdahulu membuktikan ada faktor-faktor yang mempengaruhi tingkat green konsumen, seperti pengetahuan, nilai, sikap dan perilaku (Laroche et al., 2001). Menurut Laroche et al. (2001) menemukan bahwa pengetahuan konsumen mengenai isu lingkungan merupakan prediktor yang signifikan mempengaruhi perilaku pembelian produk ramah lingkungan. Pengetahuan tentang lingkungan diakumulasi oleh konsumen dalam jangka panjang, kemudian dipadukan dengan nilai, sikap dan perilaku akhirnya mempengaruhi perilaku peduli lingkungan konsumen sehari-hari (Young et al., 2010). Oleh karena itu menurut penulis, untuk jangka pendek usaha yang dapat dilakukan pemasar adalah memberikan pengetahuan lingkungan pada konsumen. Untuk itu maka penulis melakukan studi 2 yang bertujuan untuk mengetahui apakah pemberian pengetahuan lingkungan pada konsumen secara jangka pendek dapat membuat efek green advertising menjadi lebih positif. Pada iklan cetak praktik memberi informasi ini dapat berbentuk advertorial, yaitu iklan yang disajikan dalam gaya editorial (Goodlad, et al., 1997).

Studi 2. Studi 2 bertujuan untuk menguji hipotesis 3 . Untuk mengetahui efek green adpada sikap terhadap iklan, brand attitude dan intensi membeli pada konsumen dengan pengetahuan lingkungan yang tinggi dan rendah.

Metode. Desain Penelitian Dan Partisipan. Terdapat dua kondisi eksperimen (pengetahuan lingkungan: tinggi versus rendah) between participants. Pengetahuan lingkungan dimanipulasi dengan pemberian pengetahuan lingkungan sebagai pendamping green advertising. Variabel yang diukur yaitu sikap terhadap iklan dan brand attitude (sebagai mediator) dan intensi membeli (variabel dependen). Sebanyak 87 mahasiswa FEB Unika Atma Jaya Jakarta menjadi partisipan studi 2, yang ditempatkan secara random pada satu dari dua kelompok kondisi. Terdiri dari 42 perempuan dan 45 laki-laki, berusia 17-21 tahun.

Stimulus. Sebagai stimulus, dibuat satu iklan cetak, dengan merek fiktif. Jika pada studi 1 digunakan merek riil, maka pada studi 2 ini digunakan merek fikti fagar respon partisipan tidak dipengaruhi oleh sikap mereka terhadap merek yang sudah ada. Produk dalam iklan yaitu produk pewangi pakaian sekali bilas, dengan merek fiktif EcoKlin. Pada headline iklan tertulis "Anda Dapat Hemat Air Mencuci Dengan Ecoklin. Pada bagian badan iklan tertulis "EcoKlin hanya perlu membilas sekali sajamembantu anda menghemat air setiap harinya demi menjaga persediaan air untuk generasi yang akan datang". Iklan diakhiri dengan kalimat "Ciptakan hari esok yang lebih cerah".Pada bagian kiri iklan terdapat gambar produk.Iklan ini digunakan pada kedua kelompok kondisi.Untuk kondisi green ad 
dengan pengetahuan lingkungan tinggi, penulis membuat 1 halaman narasi editorial, yang memaparkan tentang permasalahan lingkungan. Berikut kutipan sebagian narasi tersebut:

"Kerusakan lingkungan hidup dapat diartikan sebagai proses deteriorasi atau penurunan mutu (kemunduran) lingkungan. Deteriorasi lingkungan ini ditandai dengan hilangnya sumber daya tanah, air, udara, punahnya flora dan fauna liar, dan kerusakan ekosistem.............Sejak tahun 2000 telah terjadi kelangkaan air bersih di beberapa kawasan di Indonesia. Data memperlihatkan bahwa Pulau Jawa telah mengalami defisit air sebesar 2,809 miliar meter kubik per tahun........ Di Jakarta, sampai tahun 2013 cakupan layanan air bersih baru mampu menjangkau sekitar 38\% dari total jumlah populasi (10,1 juta jiwa). Penggunaan air dalam kegiatan rumah tangga sehari-hari merupakan salah satu faktor yang menyebabkan terjadinya krisis air bersih di Indonesia pada tahun 2025. Penyebab terbesar adalah untuk mencuci pakaian dan mandi............Karena itu sudah selayaknya kita menjaga bumi satu-satunya ini dari kerusakan lingkungan”.

Prosedur dan Alat Ukur. Prosedur dan alat ukur studi 2 sama dengan studi 1, dengan satu perbedaan yaitu untuk kondisi green ad dengan pengetahuan lingkungan tinggi, sebelum melihat iklan partisipan diminta membaca narasi editorial tentang permasalahan lingkungan di Indonesia.Sedangkan pada kondisi pengetahuan rendah, narasi ini tidak diberikan.

Hasil. Manipulation Check. Digunakan 5 item pengetahuan subyektif tentang lingkungan $(\alpha=0,843)$ untuk mengecek persepsi individual mengenai seberapa banyak ia tahu tentang masalah lingkungan. Item tersebut antara lain (diadaptasi dari (Konrod et al., 2011; Flynn \& Goldsmith, 1999): Saya memiliki pengetahuan tentang isu-isu lingkungan; dibandingkan orang lain saya lebih tahu tentang isu lingkungan. Pada kondisi pengetahuan tinggi, pengetahuan subyektif partisipan tentang isu lingkungan signifikan lebih tinggi dibanding kondisi pengetahuan rendah $\left(F(1,86)=9.833 ; p=0.002 M_{\text {tinggi }}=4.1268\right.$; $M_{\text {rendah }}=3.6261$ ). Selanjutnya kondisi pengetahuan rendah menjadi kondisi control. Ini menandakan bahwa manipulasi berhasil.

Sikap Terhadap Iklan, Brand Attitude, Dan Intensi Membeli. Sikap partisipan terhadap merek EcoKlin signifikan lebih tinggi pada kondisi pengetahuan tinggi, dibandingkan pada kondisi $\operatorname{kontrol}\left(F(1,86)=20.739, p=0.000, M_{\text {tinggi }}=4.6423, M_{\text {rendah }}=\right.$ 3.8188). Demikian pula intensi membeli produk pada kondisi iklan green plus pengetahuan lingkungan lebih tinggi signifikan dibandingkan pada kondisi kontrol $\left(F(1,86)=5.041, p=0.027, M_{\text {tinggi }}=4.0732, M_{\text {rendah }}=3.5978\right)$. Seperti prediksi, sikap terhadap iklan $\left(\mathrm{A}_{\mathrm{ad}}\right)$ kondisi green plus pengetahuan tidak berbeda signifikan dibanding kondisi kontrol $\left(F(1,86)=0.476, p=0.492, M_{\text {tinggi }}=4.6220, M_{\text {rendah }}=4.5054\right)$, karena tambahan pengetahuan tidak berpengaruh pada faktor periferal. Dengan demikian H3 didukung data.Ini berarti adanya tambahan pengetahuan lingkungan dibanding dengan tidak ada, mempunyai efek yang positif pada konsumen.

Uji Mediasi. Selanjutnya dilakukan uji apakah jika partisipan mendapatkan tambahan pengetahuan lingkungan (pengetahuan tinggi) maka pengaruhnya pada intensi membeli dimediasi oleh brand attitude. Untuk menguji mediasi digunakan regresi OLS dengan SPSS macro PROCESS model 4 (Hayes, 2013; Hayes \& Preacher, 2013), dengan 
bootstrap $\mathrm{n}=1000$. Intensi membeli sebagai variabel dependen, sikap terhadap iklan dan brand attitude sebagai variabel mediasi.

Hasil regresi menunjukkan bahwa sama seperti pada hasil ANOVA (Tabel 3), kondisi pengetahuan lingkungan tinggi (relatif terhadap kondisi kontrol) berpengaruh signifikan pada brand attitude $\left(\mathrm{A}_{\mathrm{B}}\right)(b=0.5662, S E=0.1142, t=4.9570, p=0.0000)$, namun tidak berpengaruh signifikan pada sikap terhadap iklan $\left(\mathrm{A}_{\mathrm{ad}}\right)(b=0.1165, S E=0.1689, t$ $=0.6898, p=0.4922)$. Brand attitude $\left(\mathrm{A}_{\mathrm{B}}\right)$ berpengaruh signifikan terhadap intensi membeli $(b=0.2840, S E=0.1314, t=2.1611, p=0.0336)$, namun tidak demikian halnya dengan sikap terhadap iklan $\left(\mathrm{A}_{\mathrm{ad}}\right)(b=-0.1491, S E=0.1509, t=-0.9879, p=0.3261)$ (Tabel 3). Indirect effect kondisi iklan green dengan pengetahuan tinggi (relatif terhadap kondisi kontrol) pada intensi membeli melalui $\mathrm{A}_{\mathrm{B}}$ signifikan $(a b=0.1608,95 \% C I$ [0.0254, 0.3803]), tetapi melalui $\mathrm{A}_{\mathrm{ad}}$ tidak signifikan ( $a b=-0.0611,95 \%$ CI [-0.2178, 0.0560]). Direct effect kondisi pengetahuan tinggi (relatif terhadap kontrol) terhadap intensi membeli tidak signifikan ( $b=-0.0871, S E=0.1650, t=-0.5277, p=0.5991)$, menandakan bahwa pada model ini terjadi full mediation (Baron dan Kenny, 1986), atau indirect-only mediation (Zhao et al., 2010). Hasil ini menunjukkan bahwa pemberian tambahan pengetahuan lingkungan efektif mempengaruhi brand attitude, yang kemudian berpengaruh positif terhadap intensi membeli.

Tabel 3. Studi 2- Brand Attitude ( $\left.\mathrm{A}_{\mathrm{B}}\right)$ Sebagai Mediator

\begin{tabular}{|c|c|c|c|c|c|c|}
\hline & \multirow{2}{*}{\multicolumn{2}{|c|}{$\begin{array}{l}A_{a d} \\
\text { Koefisien } \\
\quad(S E)\end{array}$}} & \multirow{2}{*}{\multicolumn{2}{|c|}{$\begin{array}{c}A_{B} \\
\text { Koefisien } \\
\quad(S E)\end{array}$}} & \multicolumn{2}{|r|}{ Intensi Membeli } \\
\hline & & & & & & $\begin{array}{l}\text { Koefisien } \\
\quad(S E)\end{array}$ \\
\hline Konstanta & $i_{1}$ & $\begin{array}{c}2.9784 * * \\
0.3918\end{array}$ & $i_{2}$ & $2.0202 * 0.4500$ & $i_{3}$ & $3.6434 * 0.7344$ \\
\hline Dummy & $a_{1}$ & 0.11650 .1689 & $a_{2}$ & $0.5662 * 0.1142$ & $c_{1}$ & $\begin{array}{c}-0.0871 \\
0.1650\end{array}$ \\
\hline$A_{\text {ad }}$ & & & & & $b_{1}$ & $\begin{array}{c}-0.1491 \\
0.1509\end{array}$ \\
\hline$A_{B}$ & & & & & $b_{2}$ & $0.2840 * * 0.1314$ \\
\hline
\end{tabular}

Diskusi. Hasil studi dua menunjukkan bahwa pemberian informasi tentang masalah lingkungan dapat membuat partisipan lebih terlibat dalam pesan green advertising, yang kemudian membuat sikapnya terhadap merek dan intensi membeli produk menjadi lebih positif. $A_{a d}$ yang tidak signifikan sebagai mediasi menunjukkan bahwa sikap partisipan lebih terbentuk dari konten pesan lingkungan, dibandingkan dari kemenarikan iklan (Petty ,Cacioppo \& Schumann, 1983). Seperti pada studi Konrod et al. (2011) bahwa partisipan yang menonton klip tentang lingkungan, mempersepsikan masalah polusi udara sebagai masalah yang penting, dan kemudian berpengaruh positif pada intensi menggunakan alat transportasi umum. Pada studi dua, memberi narasi masalah lingkungan dengan gaya editorial sebagai pendamping iklan green terbukti lebih efektif, dibandingkan jika partisipan hanya membaca iklan saja tanpa narasi lingkungan sebagai pendamping. 


\section{PENUTUP}

Simpulan. Dua studi pada penelitian ini menunjukkan bahwa iklan dengan pesan bertema lingkungan (green advertising) dapat berpengaruh positif pada intensi membeli produk yang diiklankan.Pengaruh positif tersebut terjadi melalui mediasi sikap terhadap merek (brand attitude). Pada studi dua intensi membeli tidak terpengaruh dari penilaian suka atau tidak suka terhadap iklan $\left(\mathrm{A}_{\mathrm{ad}}\right)$, melainkan lebih karena iklan bertema lingkungan ini membuat sikap yang positif terhadap merek. Berbeda dengan penelitian sebelumnya (Schuhwerk, at.al,1995), pada studi ini green advertising lebih efektif pada pada konsumen dengan perilaku peduli lingkungan yang sangat tinggi. Lebih lanjut, pada konsumen Indonesia, tambahan pengetahuan lingkungan yang diberikan sebagai pendamping green advertising, dapat membuat brand attitude dan intensi membeli lebih positif.

Saran. Studi yang disampaikan pada tulisan ini merupakan penelitian awal yang bertujuan untuk mengetahui efektifitas green advertising pada konsumen Indonesia. Respon positif dari partisipan berupa brand attitude dan intensi membeli yang positif terhadap green ad menunjukkan bahwa tema lingkungan dapat menjadi satu alternatif iklan yang efektif, disamping tema utilitas produk yang sudah umum. Dalam menguji efektifitas green advertising, studi ini memasukkan variabel individual differences konsumen seperti perilaku peduli lingkungan dan pengetahuan lingkungan. Bagi pemasar perlu mencari cara agar green ad juga efektif bagi konsumen dengan perilaku peduli lingkungan yang rendah dan sedang, seperti menambahkan narasi editorial tentang lingkungan seperti pada studi 2. Untuk penelitian ke depan perlu dilakukan penelitian mengenai efektifitas konten dari green advertising. Dengan menggunakan metode eksperimen, peneliti Indonesia untuk ke depannya dapat menguji efektifitas berbagai taktik kreatif penyampaian pesan lingkungan dalam iklan.

\section{DAFTARN RUJUKAN}

Aaker, J.L. (1997) Dimensions of brand personality. Journal of Marketing Research, 34, 347-356.

Ahn, H-K, Kim, H.J., \& Aggarwal, P (2013) Helping Fellow Beings: Anthropomorphized Social Causes and Role of Anticipatory Guilt.Psychological Science, 20(10), 1-6.

Banerjee, S., Gulas, C. S., \&Iyer, E. (1995) Shades of green: a multidimensional analysis of environmental advertising. Journal of advertising, 24(2), 21-31.

Chang, C. (2011) Feeling Ambivalent About Going Green Implications for Green Advertising Processing. Journal of Advertising, 40 (4), 19-31.

D'Souza, C. \&Taghian, M. (2005) Green advertising effects on attitude and choice of advertising themes.Asia Pacific journal of marketing and logistics, 17(4), 51-66.

Fishbein, M., \&Ajzen, I. (1975) Belief, Attitude, Intention, and Behavior: An Introduction to Theory and Research. Reading, MA: Addison-Wesley.

Flyn, L.R. \& Goldsmith, R.E. (1999) A short, reliable measure of subjective knowledge. Journal of Business Research, 46 (1), 57-66.

Gilg, A., Barr, S., Ford, N. (2005) Green consumption or sustainable lifestyles? Identifying the sustainable consumer.Futures, 37, 481-504. 
Hayes, A.F. (2013) Introduction to mediation, moderation, and conditional process analysis.A regression-based approach.The Guilford Press. New York.

Hayes, A.F., \& Preacher, K.J. (2013) Statistical mediation analysis with a multicategorical independent variable. British Journal of Mathematical and Statistical Psychology, 120.

Homer, P. (1995) Ad Size as indicators for perceived advertising cost and effort : The effects on memory and perceptions. Journal of Advertising, 24, 1-12.

Kronrod, A., Grinstein, A., \& Luc Wathieu, L. (2012) Go Green! Should Environmental Messages Be So Assertive? Journal of Marketing, 76, 95-102.

Laroche, M.,Bergeron, J. \&Forleo, G. B. (2001) Targeting consumers who are willing to pay more for environmentally friendly products. Journal of Consumer Marketing, 18(6) 503-520.

Lutz, R.J., MacKenzie, S.B., \&Belch, G.E. (1983) Attitude toward the ad as amediator of advertising effectiveness : Determinants and consequences. Advances in Consumer Research, 10, 532-539.

Miniard, P. W., Bhatla, S., Lord, K.R., Dickson, P. R., \&Unnava, H.R. (1991) PictureBased PersuasionProcesses and the Moderating Role of Involvement. Journalof Consumer Research, 18 (1), 92-107.

Mostafa, M. M. (2007) A hierarchical analysis of the green consciousness of the Egyptian consumer.Psychology \& Marketing, 24(5), 445-473.

Petty, R.E., Cacioppo, J.T., \&Schumann, D. (1983) Central and peripheral routes to advertising effectiveness: The moderating role of involvement. Journal of Consumer Research, 10, 135-146.

Schuhwerk, M. E. \&Lefkoff-Hagius,R. (1995) Green or Non-Green? Does Type of Appeal MatterWhen Advertising a Green Product?Journal of advertising, 24(2), 46-54.

Sen, S. \& Bhattacharya, C. B. (2001) Does Doing Good Always Lead to Doing Better? Consumer Reactions to Corporate SocialResponsibility. Journal of Marketing Research, 38(2) 225-243.

Spiller, S.A., Fitzsimons, G.J., \& Lynch Jr.,J.G. (2013) Spotlights, floodlights, and the magic number zero: Simple effects test in moderated regression. Journal of Marketing Research, L, 277-288.

Tam, K-P., Lee, S-L, \& Chao, M.M. (2013) Saving Mr. Nature: Anthropomorphism enhances connectedness to and protectiveness toward nature. Journal of Experimental Social Psychology, 49(3), 514-521

Young, W., Hwang, K., Mcdonald, S. \& Oates, C. J. (2010) Sustainable consumption: green consumer behaviour whenpurchasing products. Sustainable Development, 18 (1), 20-31.

Zhao, X., Lynch Jr. J.G., \& Chen, Q. (2010) Reconsidering Baron and Kenny: myths and truths about mediation analysis. Journal of Consumer Research, 37,197-206. 